\title{
Advances in Understanding the Acyl-CoA-Binding Protein in Plants, Mammals, Yeast, and Filamentous Fungi
}

\author{
Shangkun Qiu and Bin Zeng * \\ JiangXi Province Key Laboratory of Bioprocess Engineering, College of Life Sciences, Jiangxi Science \& \\ Technology Normal University, Nanchang 330013, China; 15738826862@163.com \\ * Correspondence: Zengtx001@aliyun.com; Tel.: +86-0791-8381-5794
}

Received: 18 December 2019; Accepted: 7 March 2020; Published: 10 March 2020

\begin{abstract}
Acyl-CoA-binding protein (ACBP) is an important protein with a size of about $10 \mathrm{kDa}$. It has a high binding affinity for $\mathrm{C}_{12}-\mathrm{C}_{22}$ acyl-CoA esters and participates in lipid metabolism. ACBP and its family of proteins have been found in all eukaryotes and some prokaryotes. Studies have described the function and structure of ACBP family proteins in mammals (such as humans and mice), plants (such as Oryza sativa, Arabidopsis thaliana, and Hevea brasiliensis) and yeast. However, little information on the structure and function of the proteins in filamentous fungi has been reported. This article concentrates on recent advances in the research of the ACBP family proteins in plants and mammals, especially in yeast, filamentous fungi (such as Monascus ruber and Aspergillus oryzae), and fungal pathogens (Aspergillus flavus, Cryptococcus neoformans). Furthermore, we discuss some problems in the field, summarize the binding characteristics of the ACBP family proteins in filamentous fungi and yeast, and consider the future of ACBP development.
\end{abstract}

Keywords: Acyl-CoA-binding protein; structure; function; plants; mammals; yeast; filamentous fungi

\section{Introduction}

Acyl-CoA-binding protein (ACBP) was first discovered in the brain of mice in 1983 and was initially named diazepam-binding inhibitor (DBI) [1]. Subsequently, ACBP and its family of proteins were found in other eukaryotes, such as animals, plants, fungi, and protozoa, as well as prokaryotes, including pathogens of some animals and plants [2]. ACBP is approximately $10 \mathrm{kDa}$. The ACBP family proteins all contain a highly conserved ACBP domain, which plays an important role in acyl-CoA binding and transport. Some ACBP family proteins also contain other domains, such as the ankyrin repeat (ANK) domain, kelch motif, transmembrane domain, ECH domain, and GOLD domain [3,4]. ACBP is a key lipid transport protein and plays an important role in intracellular lipid synthesis, vesicle transport, and gene regulation $[5,6]$. ACBP has a high affinity and specificity for long-chain acyl-CoA esters and medium-chain acyl-CoA esters, and ACBP can protect acyl-CoA esters from hydrolysis during some physiological activities, such as lipid biosynthesis and remodeling, $\beta$-oxidation, and protein acylation [2].

Recently, research on the structure and function of ACBP has mainly focused on mammals and plants. Some studies have shown that mammalian ACBP is mainly located in the cytoplasm, endoplasmic reticulum (ER), Golgi body, and nucleus [7]. Through the deletion of the ACBP gene in mice, researchers found that the biosynthesis of fat in hepatocytes was delayed when the mice were weaned. Therefore, this indicates that ACBP plays an important role in intracellular lipid synthesis and metabolism [8]. By knocking out ACBP in mice, researchers found that the content of ceramide in the hepatocytes of mutant mice decreased significantly [9]. Recent studies have shown that there are six 
ACBP family proteins in Hevea brasiliensis, among which $\mathrm{HbACBP1}$ and HbACBP2 play an important role during lipid metabolism and latex synthesis [10].

At present, research on the structure and function of ACBP family proteins in yeast and filamentous fungi is increasing, especially the important role they play in lipid metabolism. Studies have shown that the ACBP from yeast delays the growth of yeast and increases the biosynthesis of sphingolipids [11]. By deleting the Acb1 gene, which encodes ACBP in Saccharomyces cerevisiae, researchers demonstrated that $\mathrm{ACBP}$ has an important function in cell vacuole accumulation and maintaining the cell membrane structure [12]. Some studies have recently shown that overexpressing ACBP5 in Monascus ruber increased the production of Monascus pigments (MPs), the water-soluble segment, and the ethanol-soluble segment by $11.67 \%, 9.8 \%$, and $12.70 \%$, respectively [13]. ACBP is known as AoACBP in Aspergillus oryzae. Using fluorescence co-localization, studies have demonstrated that the punctate structures of AoACBP are distributed in the cytoplasm, and punctate structures exhibited microtubule-dependent motility, revealing the potential mechanism of AoACBP's involvement in lipid metabolism in A. oryzae [14]. Therefore, it is of great significance to study the action mechanism of the ACBP family proteins in organisms, especially to explain the important mechanism of the ACBP family proteins involved in lipid metabolism in yeast and filamentous fungi.

\section{General Characteristics of ACBP Structure and Function}

The ACBP family proteins which contain the ACBP domain are also named ACBD, and DBI is named ACBD1 [15]. Different ACBP homologous proteins are found in different species, which contain different numbers of ACBP. For example, there are seven kinds of ACBD family proteins in humans, among which the shortest protein containing only the ACBP domain is called ACBD1 or ACBP. ACBD5 contains 525 amino acid residues and only the ACBP domain. The other five ACBD family proteins contain not only the ACBP domain but also other domains, such as the ANK domain, GOLD domain, and ECH domain [15]. The yeast Saccharomyces carlsbergensis contains two ACBP family proteins, known as yeast ACBP types 1 and 2, which exhibit 48\% (type 1) and 49\% (type 2) conservation of amino acid residues with the human ACBP [16]. Caenorhabditis elegans contains seven ACBP family proteins, among which ACBP-1, 3, 4, 6 only contain the ACBP domain [17]. There are six ACBP family proteins in Arabidopsis thaliana, which are called AtACBP-1, 2, 3, 4, 5, 6. The ACBP family proteins in A. thaliana are the most studied plant ACBP family proteins [15].

ACBP family proteins of plants can be divided into four categories according to the different domains they contain $[18,19]$. The first class is ACBP, which has a single ACBP domain and a small molecular weight, usually consisting of $88-155$ amino acids. The second class, ANK ACBP, is usually composed of 260-370 amino acids. In addition to the ACBP domain, this ACBP family protein contains an ANK domain at the C-terminus of the protein. The third class is a large molecular weight ACBP that has a single ACBP domain, which is usually composed of $215-700$ amino acids. The fourth category is the kelch motif ACBP, which typically consists of 648 to 668 amino acids and contains a kelch domain at the C-terminus along with the ACBP domain $[10,20]$. In addition to the kelch domain and the ANK domain, ACBP family proteins in humans and mammals also contain different numbers of the ECH domain, GOLD domain, and Herpes DNAp domain [15]. Different domains have different functions. For example, ACBP interacts with other proteins through the kelch motifs and ANK domain [19]. The conserved ACBP domain of the ACBP family proteins binds with very high affinity to ligands of medium- and long-chain acyl-CoA esters [21]. ACBP binds to the ER and cell membrane through the transmembrane domain and the ANK domain $[3,22]$ (Figure 1). 
$\mathbf{a}$

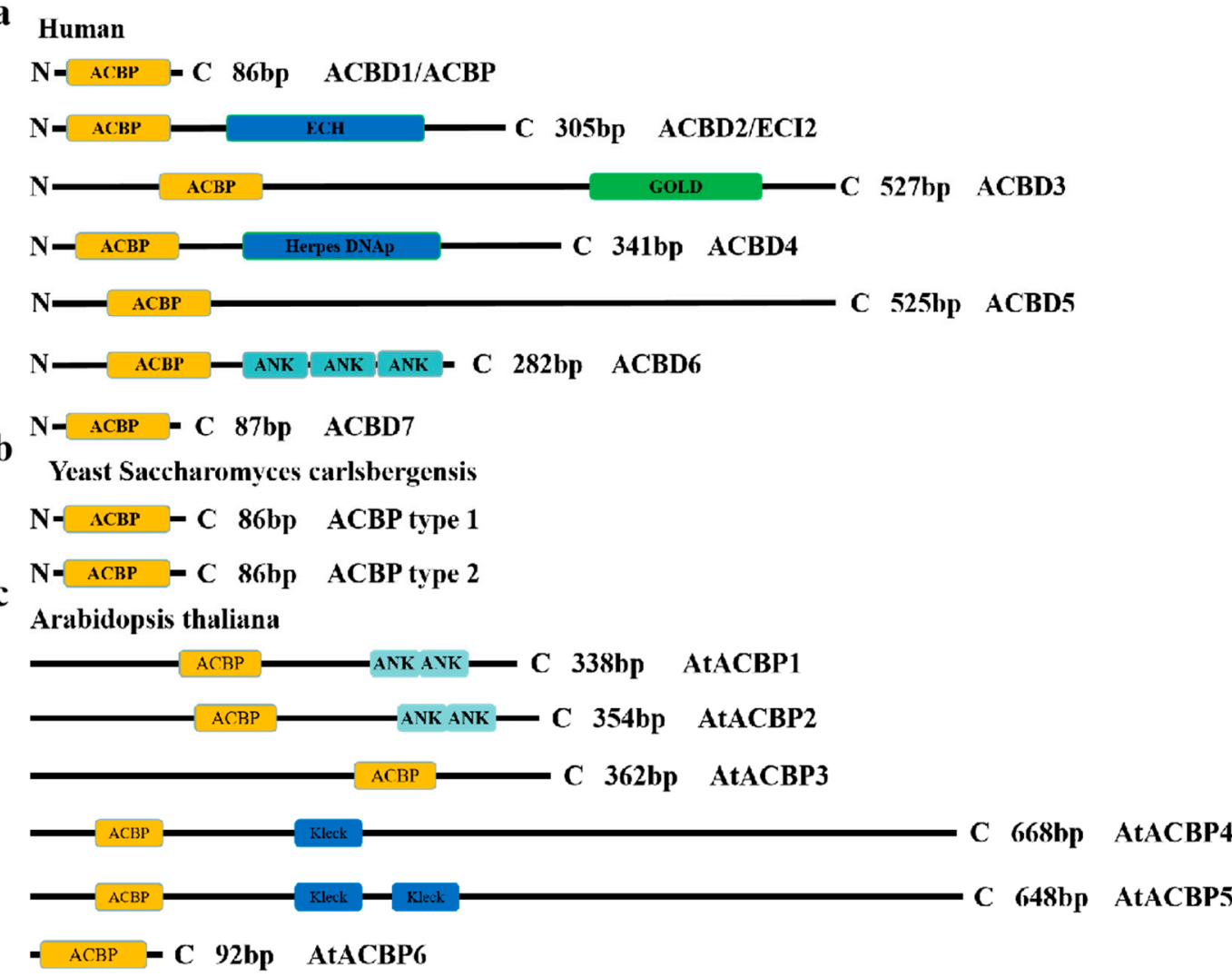

Figure 1. Schematic of key sequence domains of ACBP family proteins in humans, yeast S. carlsbergensis, and A thaliana. All ACBP family proteins contain the ACBP domain, which binds to acyl-CoA ester. (a) There are seven kinds of ACBP family proteins in humans; (b) two kinds in yeast S. carlsbergensis; and (c) six kinds in A. thaliana.

Different ACBP family proteins have different functions. For example, researchers performed a comparative lipidome analysis of 613 lipid molecules from the liver, muscle, and plasma of weaning and adult $A C B P$ knockout and wild type mice. The results show that the deficiency of ACBP affects lipid metabolism in the liver and plasma during weaning [5]. Other studies have shown that Aichi viruses replicate by interacting with ACBD3 in host cells, and the deficiency of ACBD3 in host cells can inhibit the proliferation of Aichi viruses [23]. Hepatitis $C$ virus is a pathogen that causes many chronic liver diseases, cirrhosis, and even liver cancer. Researchers knocked out the ACBD3 gene in the host cells, and the results showed that the protein expression level of the Hepatitis $C$ virus was significantly elevated, suggesting that ACBD3 inhibits viral replication [24]. ACBP from $A$. thaliana is involved in lipid metabolism and can maintain a membrane-associated acyl pool during lipid transport from the ER to the plasma membrane [20]. Some studies have shown that ACBP can affect spore formation by regulating lipid metabolism. Researchers deleted AcbA from Dictyostelium discoideum and showed that $D$. discoideum produced fewer spores compared to the wild type [25].

\section{The Function of ACBP Family Proteins in Plants}

\subsection{ACBP Family Proteins Can Promote Latex Formation}

H. brasiliensis is a critical cash crop capable of synthesizing high-quality latex, which is commercially important [26]. Recently, studies have shown that H. brasiliensis contains six ACBP family proteins that are divided into four categories. The first category, $\mathrm{HbACBP1}$, only contains the ACBP domain. The second category, HbACBP2, not only contains ACBP domain but also an ANK domain. The third category, composed of $\mathrm{HbACBP} 3$ and $\mathrm{HbACBP} 4$, contains only ACBP domains. However, the number 
of amino acids is significantly more than HbACBP1. The fourth category, composed of HbACBP4 and HbACBP5, contains not only an ACBP domain but also a kelch domain. Through RT-qPCR analysis of the expression patterns of these six ACBP family proteins, researchers found that HbACBP1 and $\mathrm{HbACBP} 2$ were mainly expressed in latex, and their expression levels were significantly higher than in other organs and tissues. HbACBP3-6 are mainly expressed in mature leaves and the male flower, indicating that they may play a critical role in the growth and development of mature leaves and male flower, while $\mathrm{HbACBP} 1$ and $\mathrm{HbACBP} 2$ mainly play an important role during latex formation. The expression patterns of ACBP family proteins in laticifers were analyzed using three methods: bark tapping (a mechanical ground), exogeneous ethrel (ET, a releaser of ethylene), and jasmonic acid (JA) stimulation. The results showed that bark tapping and JA stimulation increased the expression levels of $\mathrm{HbACBP} 1$ and $\mathrm{HbACBP2}$, whereas ET only increased the expression level of HbACBP1 [10]. ET and bark tapping can promote the production of latex $[27,28]$, and JA stimulation can promote laticifer differentiation [29], indicating that $\mathrm{HbACBP} 1$ and $\mathrm{HbACBP} 2$ play important roles in latex formation and lipid metabolism [10]. Therefore, as an important commercial resource, it is of great significance to explore the role of ACBP family proteins during the formation of latex.

\subsection{OsACBP1 and OsACBP2 Are Functionally Distinct in Oryza sativa}

O. sativa (rice) contains six homologous ACBP family proteins known as OsACBP1,2,3,4,5,6 [18]. OsACBP1 and OsACBP2 play important roles in intracellular lipid metabolism. The most common acyl-CoA esters in plants are 16:0-CoA, 18:2-CoA, and 18:3-CoA. Isothermal titration calorimetry (ITC) experiments were recently conducted to study the binding affinity of OsACBP1 and OsACBP2 for these three acyl-CoA esters. The results showed that the equilibrium dissociation constant $(\mathrm{Kd})$ value of the binding activity between OsACBP1 and the three acyl-CoA esters was 0.031-2.36 mM, while the $\mathrm{Kd}$ value of the binding activity between OsACBP2 and the three acyl-CoA esters was $0.080-0.85$ $\mathrm{mM}$. OsACBP2 had a significantly higher binding affinity for unsaturated acyl-CoA than OsACBP1, while OsACBP1 and OsACBP2 exhibited the same binding activity with 16:0-CoA. This indicates that although OsACBP1 and OsACBP2 are up to 79\% homologous, their functions in organisms are significantly different [30]. Therefore, it is of great interest to explore the biochemical properties of OsACBP to further understand its mechanism of action in O. sativa. Furthermore, since OsACBP1 and OsACBP2 both belong to the first class of ACBP family proteins, this research also revealed that the functions of ACBP family proteins from the same class might also be quite different.

\subsection{The Function of ACBP Family Proteins in A. tatiana}

A. tatiana contains six ACBP family proteins, which are the most intensively studied plant ACBP family proteins [3]. Recent studies have shown that knocking out AtACBP1 can enhance the tolerance of A. tatiana to freezing, while overexpression of AtACBP1 can enhance its sensitivity to freezing [31]. When AtACBP6 in A. tatiana was knocked out, the mutant was more sensitive to freezing than the wild type, while overexpression of AtACBP6 enhanced its tolerance to freezing [32]. This demonstrates that although AtACBP1 and AtACBP6 are both ACBP family proteins, their functions in A. tatiana against freezing are quite different. Studies have shown that AtACBP1 and AtACBP2 can bind heavy metal ions, thereby affecting their intracellular functions. Researchers reduced the tolerance of A. tatiana to $\mathrm{Pb}^{2+}$ by knocking out AtACBP1, while overexpression of AtACBP1 increased its tolerance to $\mathrm{Pb}^{2+}[33,34]$. When overexpressing AtACBP2, A. tatiana significantly increased its tolerance to $\mathrm{Cd}^{2+}$, and the protein alleviated the lipid peroxidation caused by heavy metals by participating in the repair of glycerophospholipids in the cell membrane [34,35]. AtACBP also regulates cellular physiology by binding lipids in the cell. For example, AtACBP1 can combine with very-long-chain acyl-CoAs (VLCACoAs) in the cell, and researchers found a significant decrease in very-long-chain fatty acids (VLCFAs) on cuticular waxes following the deletion of AtACBP1 [36]. AtACBP3 regulates the plant response to hypoxia by regulating the metabolism of VLCFAs [37]. Recent studies have found that AtACBP4 and AtACBP5 play important roles in seed germination and pollen development of 
A. thaliana [22,38]. AtACBP5 can also participate in the formation of the cuticle and help A. thaliana defend against pathogens and microbial infection [39].

\section{The Function of ACBP Family Proteins in Mammals}

\subsection{The Influence of Ceramide Synthesis of ACBP}

Ceramides, which are very crucial sphingolipids in cells, are important components of the cell structure and play a key role in regulating cell differentiation and growth [40]. There are six ceramide synthase (CerS) isoforms in mammals, and they are involved in the synthesis of ceramides with differing acyl chain lengths [41]. Studies have shown that acyl-CoA synthetase 5 (ACSL5) can catalyze the biosynthesis of long-chain acyl-CoA esters and influence ceramide biosynthesis in the cell through the interactions with CerS [42,43]. Recent studies have shown that by knocking out the ACBP gene in mice, the liver cytoplasm of mutant mice is unable to activate CerS3, while high-speed liver cytosol from wild type mice was able to activate CerS3. At the same time, the content of long- and very-long-chain ceramides in the mutant cells was significantly reduced [9]. These results indicate that ACBP plays an important role in ceramide synthesis. Therefore, to explore the process by which ACBP affects sphingolipid metabolism is of great significance for understanding human diseases that are triggered by sphingolipid metabolism.

\subsection{The Influence of ACBP on Obesity}

ACBP can modulate dietary behavior by regulating the glucose level and lipid metabolism in the body [44]. A recent study has shown that by inserting monoclonal anti-ACBP antibodies into mice to neutralize the extracellular pool of ACBP, the food intake of mice after starvation was reduced, and the plasma glucose levels were significantly increased. Furthermore, when tamoxifen (a method that is based on TAM induced ACBP excision) was injected into mice to remove ACBP in vivo, researchers found that the mice could still maintain normal blood glucose levels in the cells and that the metabolic changes in the plasma and brown adipose tissue were similar to those of normal mice after starvation [44]. Some research has reported that hunger causes the autophagy-dependent release of ACBP from cells, thereby leading to an increase in plasma ACBP concentrations. Neutralization of $A C B P$ showed that this process abolishes the hyperphagia after starvation of mice. At the same time, ACBP in plasma is increased in obese people and mice compared to normal people and mice [45]. Recent results indicate that the translocation of ACBP from the intracellular to the extracellular space could cause feedback inhibition of autophagy. This demonstrates that the autophagy-associated release of ACBP elicits feedback inhibition of autophagy through different mechanisms [46]. Therefore, ACBP plays an important role in regulating the blood glucose level, lipid metabolism, and diet behavior in the body. Exploring its function will contribute to the development of new methods for treating obesity.

\section{The Function of ACBP Family Proteins in Filamentous Fungi}

\subsection{ACBP from M. ruber Can Promote the Synthesis of Monascus Pigments}

M. ruber is a traditional food fermentation strain with a long history of use in Asia [47,48]. MPs are an important synthetic product of M. ruber that have anti-inflammatory, anti-cancer, anti-atherosclerotic, anti-diabetic, and other functions [49]. There are two synthetic routes of MPs in M. ruber, namely synthesis by polyketide polymerase and fatty acid synthetase [50]. Researchers have recently expressed a fusion protein of the maltose-binding protein (MBP) and MrACBP in E. coli Rosetta DE3. The binding affinity of MrACBP was determined for different ligands using the microscale thermophotoresist (MST) binding assay. It was demonstrated that MrACBP in M. ruber had a high binding affinity for myristoyl-CoA, palmitoyl-CoA, and octyl-CoA, while the highest binding affinity was for myristoyl-CoA. Homologous overexpression of ACBP5 in M. ruber showed that MPs increased by $11.67 \%$. MPs are synthesized by polyketide, which is generated by acyl-CoA [50]. It is speculated 
that overexpression of ACBP5 results in the expansion of the intracellular acyl-CoA pool, thereby improving this process. The results also demonstrate that the content of water-soluble pigment and ethanol-soluble pigment increased by $9.80 \%$, and $12.70 \%$ via overexpression of ACBP5, which may be related to biomass. Therefore, MrACBP preferentially binds to myristoyl-COA and can affect MPs biosynthesis in the cell [13].

\subsection{ACBP from A. oryzae Preferentially Binds to Long-Chain Acyl-CoA}

A. oryzae is an important filamentous fungi and is widely used in food fermentation. A. oryzae is unable to produce mycotoxin; however, it can produce a variety of enzymes with biological activities, including protease, peptidase, and amylase, that are useful during the process of brewing soy sauce to increase its nutrition, flavor, and taste [51]; thus, it is considered as a safe strain for food fermentation [52]. Therefore, exploring the function of AoACBP in lipid metabolism of A. oryzae is conducive to developing different types of low-fat food. Recently, researchers fused enhanced green fluorescent protein (EGFP) and AoACBP to facilitate subcellular localization. The results showed that AoACBP is mainly located in the punctate structure of the cytoplasm, and it exhibits bidirectional mobility. Then the researchers treated $A$. oryzae with nocodazole, a microtubule-depolymerizing reagent, and the bidirectional motility of AoACBP disappeared after $10 \mathrm{~min}$ of treatment. When $A$. oryzae was treated with the actin defascinating reagent latrunculin $B$ for $10 \mathrm{~min}$, the bidirectional motility of AoACBP was still observable, suggesting that the bidirectional movement in punctate structures depends more on microtubules than actin [14].

To determine the biochemical properties of AoACBP in A. oryzae and its function in lipid metabolism, the AoACBP gene was cloned from A. oryzae, and the fusion protein of MBP and AoACBP were expressed and purified in E. coli cells. The activity of AoACBP with palmitoyl-CoA and myristoyl-CoA was analyzed using an MST assay. The results showed that AoACBP has a high binding affinity for palmitoyl-CoA and myristoyl-CoA, and the binding affinity for palmitoyl-CoA was the highest, indicating that AoACBP preferentially binds to long-chain acyl-CoA in A. oryzae [53].

\subsection{Aoacb2 Is Secreted via the Unconventional Protein Secretion (UPS) Pathway in A. oryzae}

By performing a BLAST search using the Acb1 gene sequence of $S$. cerevisiae, a recent study showed that A. oryzae has another ACBP family protein besides AoACBP, which was named Aoacb2. The researchers constructed a conditional strain with an HA tag attached to the C-terminus of Aoacb2 and expressed it to analyze the secretion of Aoacb2-HA in the medium by Western blot with an anti-HA antibody. To eliminate the interference of cell lysis, the researchers used EGFP connected with HA as the negative control and detected Aoacb2-HA and EGFP-HA in the supernatant of the carbon-starved culture. A small amount of EGFP-HA and a large amount of Aoacb2-HA were found in the supernatant, which indicates that cell lysis released part of EGFP-HA, while a large amount of Aoacb2-HA was secreted into the culture medium by A. oryzae. To verify whether AoACBP can also be secreted into the medium under the same conditions, the researchers also conducted an AoACBP secretion experiment. The results showed that AoACBP cannot be secreted into the medium under the same conditions. This indicates that carbon starvation induces AoAcb2 to be unconventionally secreted into the culture medium [54]. Therefore, two types of ACBP from A. oryzae undergo different secretion pathways. Understanding the detailed molecular mechanism of unconventional secretion may be advantageous for developing new biotechnological strategies to produce heterologous expression proteins.

\subsection{The Function of ACBP from Aspergillus flavus (A. flavus) May Affect Aflatoxin Production}

A. flavus is a common plant and a human pathogen that can produce the carcinogenic aflatoxin. Aflatoxin is a secondary metabolite of A. flavus, and its biosynthesis is strongly influenced by various environmental factors [55]. Contamination of crops, such as cotton, peanuts, maize, and tree nuts by aflatoxin creates a substantial food safety risk, especially in developing countries [56]. Researchers 
used KEGG pathway analysis to investigate the expression levels of some proteins in A. flavus and demonstrated that the degradation of valine, leucine, and isoleucine in solid media can increase the synthesis of acyl-CoA compared to that in liquid media. Acyl-CoA, which is the precursor of aflatoxin, is important for aflatoxin synthesis [57]. Researchers cultured A. flavus in medium containing 2-phenylethanol and used GO Enrichment and KEGG pathway analysis to study the expression levels of some proteins in A. flavus. The results demonstrated that the related genes of aflatoxin, pyruvate, and propionate biosynthesis were significantly downregulated. Propionate is the precursor of acyl-CoA, so it may be the reduction in propionate leads to decreased acyl-CoA and aflatoxin [58]. Acyl-CoA is a critical cofactor in all organisms because it functions in numerous biosynthetic and energy-yielding metabolic pathways. Therefore, it is speculated that ACBP, as an acyl-CoA transport protein, may play a key role in aflatoxin synthesis [59].

\section{The Function of ACBP Family Proteins in Yeast}

\subsection{ACBP Can Regulate the Synthesis and Degradation of NADPH in Yeast Yarrowia lipolytica}

Among oil-producing microorganisms, NADPH is mainly produced through the pentose phosphate pathway, which plays an important role in intracellular lipid synthesis [60]. Recent research has shown that overexpression of $\mathrm{NADP}^{+}$-dependent glucose-6-phosphate dehydrogenase (encoded by ZWF1), an important enzyme in pentose photosphate pathway, results in a large reduction in intracellular biomass from $15.0 \mathrm{~g} / \mathrm{L}$ to $9.5 \mathrm{~g} / \mathrm{L}$. It is suggested that the overexpression of ZWF1 may result in the imbalance of the NADPH/NADP ${ }^{+}$content in the cell. When ACBP was overexpressed alone, the total amount of lipids in the cell increased from $9 \%$ to $25.1 \%$. When ZWF1 and ACBP were overexpressed at the same time, the growth defects caused by the overexpression of ZWF1 alone were reversed, and a large amount of lipids were synthesized in the cells. It is speculated that overexpression of ACBP led to a large amount of acyl-CoA synthesis in the cells, leading to the oxidation of some NADPH, thus alleviating the imbalance of the NADPH/NADP ${ }^{+}$content produced by $\mathrm{ZWF} 1$ overexpression. Therefore, ACBP is an important protein for intracellular lipid synthesis that can regulate the production and degradation of intracellular NADPH [61].

\subsection{The function of $A C B P$ from $C$. neoformans}

C. neoformans is a human fungal pathogen that causes devastating cryptococcal meningitis, which threatens the lives of hundreds of thousands of people every year $[62,63]$. Recently, researchers examined the transcript levels of the ACB1 gene during bisexual mating and deleted the ACB1 gene in the hyper-filamentous serotype D strain XL280 $\alpha$ and its congenic strain XL280a. The results show that Acb1 plays a crucial role in mating, and the acb1 $\Delta$ mutant exhibited dramatically reduced filamentation relative to the wild type. Additionally, the introduction of the wild-type allele of ACB1 into the acb1 $\triangle$ mutant restored the filamentation defect. Researchers made a Y80A mutated allele of Acb1 through site-directed mutagenesis and introduced it into the acb1 $\triangle$ mutant. The results showed that the Y $80 \mathrm{~A}$ mutant could not restore the filamentation defect in the mutant [64]. The results also showed that the $\mathrm{Y} 80$ residue in the acyl-CoA binding domain is critical for the function of Acb1. Therefore, Acb1 regulates mycelium morphology by binding acyl-CoA, and this acyl-CoA binding ability is critical for the function of Acb1 during filamentation. Exploring the function of Acb1 can help to develop new methods to reduce the risk of pathogens.

The CnACBP protein from C. neoformans was expressed in E. coli BL21 (DE3) and purified using a Ni-NTA superflow column. The OCoA and model membranes were then added to the solution containing the target protein. The changes in the secondary structure of the protein in solution after the addition of OCoA and the model membranes were detected by Circular dichroism spectrometer (CD). The results showed that when OCoA was added to the protein solution, the CD spectrum of the protein did not change, indicating that the binding of OCoA had no effect on the secondary structure of CnACBP. When the model membranes containing 1-palmitoyl-2-oleoyl-sn-glycero-3-phosphoo-(1'-rac-glycerol) 
(POPG) were added to the protein solution, changes in the CnACBP CD spectra were detected, indicating that the secondary structure of the protein was affected by POPG addition. However, after addition of either the phospholipid 1-palmitoyl-2-oleoyl-sn-glycero-3-phosphocholine (POPC) or a mixture of POPG and POPC, the CD spectra of CnACBP did not change, indicating that POPC and the mixture of POPC and POPG had no effect on the CnACBP secondary structure. This indicates that $\mathrm{CnACBP}$ preferentially binds anion membranes over neutral membranes. By exploring the effects of OCoA and phospholipids on the structure and stability of CnACBP, it is helpful to understand the process of CnACBP transport to different parts of cells after binding with lipids [65].

\subsection{Depletion or Overexpression of ACBP May Affect Intracellular Lipid Synthesis and Vacuole Function}

An ACBP family protein is encoded by the Acb1 gene in yeast. Recently, studies have shown that through the depletion of the Acb1 gene, a large number of different shaped vesicles accumulated in the cell, and the structure of the plasma membrane also changed significantly. The multi-layered plasma membrane structures appeared in the plasma membrane [11,12]. When the researchers depleted the Acb1 gene, there was a significant accumulation of stearyl-COA in the cells and a significant decrease in myristoyl-COA, palmi-toleoyl-COA, and oleoyl-COA. This shows that ACBP plays an important role in intracellular lipid synthesis. After overexpression of the Acb1 gene, the lipid content in cells increased significantly, as did the acyl-CoA ester pool, indicating that ACBP can not only promote lipid synthesis but also the formation of an acyl-CoA ester pool [16,66].

Some research has shown that after depleting the Acb1 gene, the isolated vacuole cannot fuse with a homotypic vacuole, which may be because there is no ceramide in the vacuole after depleting the Acb1 gene, leading to the absence of SNARE proteins in the vacuolar membrane [12].

\section{The Binding Characteristics of ACBP Family Proteins from Yeast and Filamentous Fungi}

Some studies have shown that acyl-CoA esters have important physiological functions in the cell and that they play a key role in regulating ion channels, ion pumps, gene expression, and membrane fusion [43,67]. ACBP and its family of proteins bind to acyl-CoA esters through the ACBP domain and participate in different metabolic regulation of the body [2] (Table 1). Therefore, analysis of the binding relationship between the ACBP family proteins and acyl-CoA esters is helpful to further understand the important functions of ACBP in lipid metabolism. In filamentous fungi and yeast, ACBP and its family of proteins have a high binding affinity for acyl-CoA esters. Researchers analyzed the binding affinity of AoACBP from A. oryzae for nine kinds of acyl-CoA esters, including butyryl-COA, hexanoyl-COA, palmitoyl-COA, and myristoyl-COA. The results showed that the binding affinity of AoACBP towards palmitoyl-CoA, myristoyl-CoA, stearoyl-CoA, and eicosanoyl-CoA was significantly higher than that towards the other five acyl-CoA esters, indicating that AoACBP preferentially binds to long-chain acyl-CoA. The researchers applied the same method to determine the binding affinity of ScACBP from S. cerevisiae with nine different acyl-CoA esters. The results showed that ScACBP can bind $\mathrm{C}_{4}-\mathrm{C}_{16}$ acyl-CoA esters and that it has the highest binding affinity for palmitoyl-COA and myristoyl-COA. This indicates that when ScACBP binds $\mathrm{C}_{4}-\mathrm{C}_{16}$ acyl-CoA esters, long-chain acyl-CoA is preferred. However, ScACBP showed a lower binding affinity for stearyl-COA and eicosanoyl-COA, indicating that the binding affinity for very-long-chain acyl-CoA is lower [54,68]. The binding affinity of MrACBP of $M$. ruber for $\mathrm{C}_{4}-\mathrm{C}_{22}$ acyl-CoA was analyzed by MST assay and showed that MrACBP has a high binding affinity for myristoyl-COA, palmitoyl-COA, and octane-COA. The binding affinity for myristoyl-COA was the highest, indicating that MrACBP preferentially binds myristoyl-COA [13]. There are two ACBP family proteins in yeast S. carlsbergensis, among which ACBP type 1 exhibits a high binding affinity for palmitoyl-CoA [16]. Recently, a study using size exclusion chromatography (SEC) revealed that CnACBP from C. neoformans has a high binding affinity for oleoyl-COA and palmitoyl-COA, which can affect the spatial structure and stability of CnACBP [65] (Table 2). 
Table 1. The proposed function of Acyl-CoA-binding protein (ACBP) from filamentous fungi and yeast.

\begin{tabular}{|c|c|c|c|}
\hline Fungus & $\begin{array}{l}\text { ACBP Family } \\
\text { Proteins }\end{array}$ & Proposed Function & Reference \\
\hline \multirow[t]{2}{*}{ Aspergillus oryzae } & AoACBP & $\begin{array}{l}\text { It localizes to punctate structures and } \\
\text { preferentially binds to long-chain acyl-CoA }\end{array}$ & {$[14,54]$} \\
\hline & Aoacb2 & $\begin{array}{l}\text { It is dispersed in the cytoplasm, important for } \\
\text { the growth and undergoes unconventional } \\
\text { secretion }\end{array}$ & [54] \\
\hline Aspergillus flavus & ACBP & It may affect aflatoxin production & [57] \\
\hline Monascus ruber & MrACBP & $\begin{array}{l}\text { It improves the expansion of the intracellular } \\
\text { acyl-CoA pool and increases MPs synthesis }\end{array}$ & [13] \\
\hline $\begin{array}{l}\text { Saccharomyces } \\
\text { cerevisiae }\end{array}$ & Acb1p & $\begin{array}{l}\text { It is required for normal vacuole function and } \\
\text { could improve the formation of the acyl-CoA } \\
\text { ester pool and ceramide }\end{array}$ & [12] \\
\hline $\begin{array}{l}\text { Yeast Yarrowia } \\
\text { lipolytica }\end{array}$ & ACBP & $\begin{array}{c}\text { It can improve acyl-CoA synthesis and regulates } \\
\text { the production and degradation of intracellular } \\
\text { NADPH }\end{array}$ & [61] \\
\hline $\begin{array}{l}\text { Cryptococcus } \\
\text { neoformans }\end{array}$ & Acb1 & $\begin{array}{l}\text { It is important for mating and filamentation, and } \\
\text { preferentially binds to anion lipid membranes }\end{array}$ & {$[64,65]$} \\
\hline $\begin{array}{l}\text { Saccharomyces } \\
\text { carlsbergensis }\end{array}$ & ACBP type1/2 & $\begin{array}{l}\text { It can bind to acyl-CoA and improve } \\
\text { the expansion of the intracellular acyl-CoA pool }\end{array}$ & [16] \\
\hline
\end{tabular}

Table 2. Binding Characteristics of ACBP from Filamentous Fungi and Yeast with Acyl-CoA Esters.

\begin{tabular}{|c|c|c|c|}
\hline Fungus & Proteins & Acyl-CoA Ester Binding & References \\
\hline \multirow{9}{*}{ Aspergillus oryzae } & \multirow{9}{*}{ AoACBP } & C4:0 Butyryl-CoA & [57] \\
\hline & & C6:0 Hexanoyl-CoA & [57] \\
\hline & & C8:0 Octanoyl-CoA & [57] \\
\hline & & C10:0 Decanoyl-CoA & [57] \\
\hline & & C12:0 Dodecanoyl-CoA & [57] \\
\hline & & C14:0 myristoyl-CoA & {$[53,57]$} \\
\hline & & C16:0 palmitoyl-CoA & {$[53,57]$} \\
\hline & & C18:0 Stearoyl-CoA & [57] \\
\hline & & C20:0 Eicosanoyl-CoA & [57] \\
\hline \multirow{9}{*}{ Saccharomyces cerevisiae } & \multirow{9}{*}{ ScACBP } & C4:0 Butyryl-CoA & [57] \\
\hline & & C6:0 Hexanoyl-CoA & [57] \\
\hline & & C8:0 Octanoyl-CoA & [57] \\
\hline & & C10:0 Decanoyl-CoA & [57] \\
\hline & & C12:0 Dodecanoyl-CoA & [57] \\
\hline & & C14:0 myristoyl-CoA & [57] \\
\hline & & C16:0 palmitoyl-CoA & [57] \\
\hline & & C18:0 Stearoyl-CoA & [57] \\
\hline & & C20:0 Eicosanoyl-CoA & [57] \\
\hline \multirow{10}{*}{ Monascus ruber } & \multirow{10}{*}{ MrACBP } & C4:0 Butyryl-CoA & [14] \\
\hline & & C6:0 Hexanoyl-CoA & {$[14]$} \\
\hline & & C8:0 Octanoyl-CoA & [14] \\
\hline & & C10:0 Decanoyl-CoA & [14] \\
\hline & & C12:0 Dodecanoyl-CoA & [14] \\
\hline & & C14:0 myristoyl-CoA & {$[14]$} \\
\hline & & C16:0 palmitoyl-CoA & {$[14]$} \\
\hline & & C18:0 Stearoyl-CoA & [14] \\
\hline & & C20:0 Eicosanoyl-CoA & [14] \\
\hline & & C22:0 Acyl-CoA & [14] \\
\hline
\end{tabular}


Table 2. Cont.

\begin{tabular}{cccc}
\hline Fungus & Proteins & Acyl-CoA Ester Binding & References \\
\hline Saccharomyces carlsbergensis & ACBP type 1 & C16:0 palmitoyl-CoA & {$[16]$} \\
\hline \multirow{2}{*}{ Cryptococcus neoformans } & CnACBP & C18:1 oleoyl-CoA & {$[58]$} \\
& & C16:0 palmitoyl-CoA & {$[58]$} \\
\hline
\end{tabular}

\section{Conclusions and Future Perspectives}

In recent years, the research on ACBP and its family of proteins has increased, especially for mammals and plants. For example, $\mathrm{HbACBP} 1$ and $\mathrm{HbACBP} 2$ play an important role in latex production and lipid metabolism. However, the specific mechanism during the formation of latex by H. brasiliensis is still unclear and needs to be further explored [10]. Latex as an important commercial resource [26]; therefore, exploring the mechanism of $\mathrm{HbACBP}$ in latex formation lays an important foundation for developing high-quality latex and increasing latex production. By studying the structure and function of OsACBP1 and OsACBP2 from O. sativa, researchers demonstrated that although these proteins have high homology, there are significant differences in structure and function. Moreover, the characteristics of OsACBP1 and OsACBP2 for binding acyl-CoA esters are still unclear and require further exploration [30]. ACBP can interact with CerS in mice cells and affect ceramide and sphingolipid synthesis. However, the mechanism still needs to be further explored [9]. ACBP family proteins play an important role during lipid metabolism in the cell. Exploring the structure and physiological function of the ACBP family proteins is of great significance to improve the production of oil crops and explore the pathogenesis of diseases caused by lipid metabolic disorders.

Research of ACBP family proteins in filamentous fungi and fungal pathogens is relatively uncommon. The function of ACBP during lipid metabolism in filamentous fungi and its important role in physiological function have been confirmed. For example, the ACBP family proteins in A. oryzae and yeast can combine a variety of different acyl-CoA esters, which play an important role in the normal physiological function of the cell [68]. The unconventional secretion of ACBP exists in A. oryzae, yeast, and some mammals, but its potential mechanism remains to be explored $[44,54,69]$. ACBP in M. rubers can affect MPs synthesis; however, the mechanism remains to be explored [13]. A. flavus and C. neoformans are important pathogens, but there are few studies on ACBP function in them. Exploring the function of ACBP in fungal pathogens can contribute to the development of new methods to reduce the risk of pathogens. At present, most of the studies on ACBP family proteins in filamentous fungi are mainly focused on its functions in A. oryzae and M. ruber. However, the specific roles of the ACBP family proteins in lipid metabolism and their influence on the physiological functions of mycelium are rarely involved, and there is little related research on ACBP family proteins in other filamentous fungi $[13,53,65,68]$. There are two ACBP family proteins in A. oryzae. However, the current research on the function of ACBP in A. oryzae is limited to the binding affinity to its ligands. Research on the structure of ACBP family proteins and their effect on the physiological function of the cell is still lacking and needs to be further explored. As a food safety strain, A. oryzae has been used in the food fermentation for thousands of years. Exploring the structure and function of ACBP family proteins in A. oryzae lays an important foundation for further development of low-fat foods and further application of $A$. oryzae in the food industry [52].

Author Contributions: S.Q. mainly participated in the data collection and article design, including article writing, chapter design, and graphic design. B.Z. mainly provided technical support and financial assistance. All authors have read and agreed to the published version of the manuscript.

Funding: This research was supported by funds from project in China (No.31460447, 31171731, 20142BDH80003, 2013-CXTD002, 3000035402, 00001384, 30000411, 300098020110, 300098030105, “555 talent project" of Jiangxi Province), Jiangxi Province Key Laboratory of Bioprocess Engineering, and Co-Innovation Center for In Vitro Diagnostic Reagents and Devices of Jiangxi Province.

Acknowledgments: We are grateful to the other staff in our laboratory for their assistance in this article. The authors thank them for their long-standing support of this scientific work. 
Conflicts of Interest: The authors declare no competing financial interests.

\section{References}

1. Adhikari, P.; Allison, G.; Whittle, B.; Verma, N.K. Isolation, characterization, and purification to homogeneity of an endogenous polypeptide with agonistic action on benzodiazepine receptors. Proc. Natl. Acad. Sci. USA 1983, 80, 3531-3535.

2. Burton, M.; Rose, T.M.; Faergeman, N.J.; Knudsen, J. Evolution of the acyl-CoA binding protein (ACBP). Biochem. J. 2005, 392, 299-307. [CrossRef] [PubMed]

3. Xiao, S.; Chye, M.L. New roles for acyl-CoA-binding proteins (ACBPs) in plant development, stress responses and lipid metabolism. Prog. Lipid Res. 2011, 50, 141-151. [CrossRef] [PubMed]

4. Fan, J.; Liu, J.; Culty, M.; Papadopoulos, V. Acyl-coenzyme A binding domain containing 3 (ACBD3; PAP7; GCP60): An emerging sig-naling molecule. Prog. Lipid Res. 2010, 49, 218-234. [CrossRef] [PubMed]

5. Gallego, S.F.; Sprenger, R.R.; Neess, D.; Pauling, J.K.; Ejsing, C.S. Quantitative lipidomics reveals age-dependent perturbations of whole-body lipid metabolism in acbp deficient mice. BBA Mol. Cell Biol. Lipids 2016, 1862, 145-155. [CrossRef] [PubMed]

6. Knudsen, J.; Jensen, M.V.; Hansen, J.K.; Faergeman, N.J.; Neergaard, T.B.; Gaigg, B. Role of acyl-CoA binding protein in acyl-CoA transport, metabolism and cell signaling. Mol. Cell. Biochem. 1999, 192, 95-103. [CrossRef]

7. Hansen, J.S.; Faergeman, N.J.; Kragelund, B.B.; Knudsen, J. Acyl-CoA-binding protein (ACBP) localizes to the endoplasmic reticulum and Golgi in a ligand-dependent manner in mammalian cells. Biochem. J. 2008, 410, 463-472. [CrossRef]

8. Neess, D.; Bloksgaard, M.; Bek, S.; Marcher, A.B.; Elle, I.C.; Helledie, T.; Due, M.; Pagmantidis, V.; Finsen, B.; Wilbertz, J.; et al. Disruption of the acyl-CoA-binding protein gene delays hepatic adaptation to metabolic changes at weaning. J. Biol. Chem. 2011, 286, 3460-3472. [CrossRef]

9. Ferreira, N.S.; Engelsby, H.; Neess, D.; Kelly, S.L.; Volpert, G.; Merrill, A.H.; Futerman, A.H.; Færgeman, N.J. Regulation of very-long acyl chain ceramide synthesis by acyl-CoA binding protein. J. Biol. Chem. 2017, 292, 7588-7597. [CrossRef]

10. Nie, Z.; Wang, Y.; Wu, C.; Li, Y.; Kang, G.; Qin, H.; Zeng, R. Acyl-CoA-binding protein family members in laticifers are possibly involved in lipid and latex metabolism of Hevea brasiliensis (the Para rubber tree). BMC Genom. 2018, 19, 5. [CrossRef]

11. Gaigg, B.; Neergaard, T.B.; Schneiter, R.; Hansen, J.K.; Faergeman, N.J.; Jensen, N.A.; Andersen, J.R.; Friis, J.; Sandhoff, R.; Schrøder, H.D.; et al. Depletion of acyl-coenzyme A-binding protein affects sphingolipid synthesis and causes vesicle accumulation and membrane defects in Saccharomyces cerevisiae. Mol. Biol. Cell 2001, 12, 1147-1160. [CrossRef] [PubMed]

12. Faergeman, N.J.; Feddersen, S.; Christiansen, J.K.; Larsen, M.K.; Schneiter, R.; Ungermann, C.; Mutenda, K.; Roepstorff, P.; Knudsen, J. Acyl-CoA-binding protein, Acb1p, is required for normal vacuole function and ceramide synthesis in Saccharomyces cerevisiae. Biochem. J. 2004, 380, 907-918. [CrossRef] [PubMed]

13. Long, C.; Liu, M.; Chen, X.; Wang, X.; Ai, M.; Cui, J.; Zeng, B. The acyl-CoA binding protein affects monascus pigment production in Monascus ruber CICC41233. 3 Biotech 2018, 8, 121. [CrossRef] [PubMed]

14. Kawaguchi, K.; Kikuma, T.; Higuchi, Y.; Takegawa, K.; Kitamoto, K. Subcellular localization of acyl-coa binding protein in aspergillus oryzae is regulated by autophagy machinery. Biochem. Biophys. Res. Commun. 2016, 480, 8-12. [CrossRef] [PubMed]

15. Neess, D.; Bek, S.; Engelsby, H.; Gallego, S.F.; Fargeman, N.J. Long-chain acyl-CoA esters in metabolism and signaling: Role of acyl-CoA binding proteins. Prog. Lipid Res. 2015, 59, 1-25. [CrossRef] [PubMed]

16. Knudsen, J.; Faergeman, N.J.; Skøtt, H.; Hummel, R.; Børsting, C.; Rose, T.M.; Andersen, J.S.; Højrup, P.; Roepstorff, P.; Kristiansen, K. Yeast acyl-CoA-binding protein: Acyl-CoA-binding affinity and effect on intracellular acyl-CoA pool size. Biochem. J. 1994, 302, 479-485. [CrossRef]

17. Elle, I.C.; Simonsen, K.T.; Olsen, L.C.; Birck, P.K.; Ehmsen, S.; Tuck, S.; Le, T.T.; Færgeman, N.J. Tissue-and paralogue-specific functions of acyl-CoA-binding proteins in lipid metabolism in Caenorhabditis elegans. Biochem. J. 2011, 437, 231-241. [CrossRef]

18. Meng, W.; Su, Y.; Saunders, R.; Chye, M. The rice acyl-CoA-binding protein gene family: Phylogeny, expression and functional analysis. New Phytol. 2011, 189, 1170-1184. [CrossRef] 
19. Du, Z.Y.; Arias, T.; Meng, W.; Chye, M.L. Plant acyl-CoA-binding proteins: An emerging family involved in plant development and stress responses. Prog. Lipid Res. 2016, 63, 165-181. [CrossRef]

20. Nadia, R.; Baoshan, W.; Longjiang, Y.; Maoteng, L. Functional and structural diversity of acyl-CoA binding proteins in oil crops. Front. Genet. 2018, 9, 182.

21. Chye, M.L. Arabidopsis cDNA encoding a membrane-associated protein with an acyl-CoA binding domain. Plant Mol. Biol. 1998, 38, 827-838. [CrossRef] [PubMed]

22. Hsiao, A.S.; Haslam, R.P.; Michaelson, L.V.; Liao, P.; Chen, Q.F.; Sooriyaarachchi, S.; Mowbray, S.L.; Napier, J.A.; Tanner, J.A.; Chye, M.L. Arabidopsis cytosolic acyl-CoA-binding proteins ACBP4, ACBP5 and ACBP6 have overlapping but distinct roles in seed development. Biosci. Rep. 2014, 35, e00165. [CrossRef] [PubMed]

23. Huang, J.Z.; Li, Y.; Zhang, L.L. The Role of ACBD3 in Pathogens Replication. Prog. Biochem. Biophys. 2017, 44, 198-203.

24. Hong, Z.; Yang, X.; Yang, G.; Zhang, L. Hepatitis C virus NS5A competes with PI4KB for binding to ACBD3 in a genotype-dependent manner. Antivir. Res. 2014, 10, 50-55. [CrossRef] [PubMed]

25. Anjard, C.; Loomis, W.F. Peptide signaling during terminal differentiation of Dictyostelium. Proc. Natl. Acad. Sci. USA 2005, 102, 7607-7611. [CrossRef]

26. Van Beilen, J.B.; Poirier, Y. Establishment of new crops for the production of natural rubber. Trends Biotechnol. 2007, 25, 522-529. [CrossRef]

27. Abraham, P.D.; Wycherley, P.R.; Pakianathan, S.W. Stimulation of latex flow in Hevea brasiliensis of 4-amino-3, 5, 6-trichloropicolinic acid and 2- chloroethane-phosphonic acid. Rubber Chem. Technol. 1972, 45, 883-899. [CrossRef]

28. Annamalainathan, K.; Krishnakumar, R.; Jacob, J.L. Tapping induced changes in respiratory metabolism, ATP production and reactive oxygen species scavenging in Hevea. J. Rubber Res. 2001, 4, 245-254.

29. Hao, B.Z.; Wu, J.L. Laticifer differentiation in Hevea brasiliensis: Induced by exogenous jasmonic acid and linolenic acid. Ann. Bot. 2000, 85, 37-43. [CrossRef]

30. Guo, Z.H.; Chan, W.H.Y.; Kong, G.K.W.; Hao, Q.; Chye, M.L. The first plant acyl-CoA-binding protein structures: The close homologues OsACBP1 and OsACBP2 from rice. Acta Crystallogr. D 2017, 73, 438-448. [CrossRef]

31. Du, Z.Y.; Xiao, S.; Chen, Q.F.; Chye, M.L. Depletion of the membrane-associated acyl-CoA-binding protein ACBP1 enhances the ability of cold acclimation in Arabidopsis. Plant Physiol. 2010, 152, 1585-1597. [CrossRef] [PubMed]

32. Chen, Q.F.; Xiao, S.; Chye, M.L. Overexpression of the Arabidopsis 10-kilodalton acyl-coenzyme A-binding protein ACBP6 enhances freezing tolerance. Plant Physiol. 2008, 148, 304-315. [CrossRef] [PubMed]

33. Xiao, S.; Gao, W.; Chen, Q.F.; Ramalingam, S.; Chye, M.L. Overexpression of membrane-associated acyl-CoA-binding protein ACBP1 enhances lead tolerance in Arabidopsis. Plant J. 2008, 54, 141-151. [CrossRef]

34. Gao, W.; Xiao, S.; Li, H.Y.; Tsao, S.W.; Chye, M.L. Arabidopsis thaliana acyl-CoA-binding protein ACBP2 interacts with heavy-metal-binding farnesylated protein AtFP. New Phytol. 2009, 181, 89-102. [CrossRef] [PubMed]

35. Gao, W.; Li, H.Y.; Xiao, S.; Chye, M.L. Acyl-CoA-binding protein 2 binds lysophospholipase 2 and lysoPC to promote tolerance to cadmium-induced oxidative stress in transgenic Arabidopsis. Plant J. 2010, 62, 989-1003. [CrossRef] [PubMed]

36. Xue, Y.; Xiao, S.; Kim, J.; Lung, S.C.; Chen, L.; Tanner, J.A.; Suh, M.C.; Chye, M.L. Arabidopsis membrane-associated acyl-CoA-binding protein ACBP1 is involved in stem cuticle formation. J. Exp. Bot. 2014, 65, 5473-5483. [CrossRef]

37. Xie, L.J.; Yu, L.J.; Chen, Q.F.; Wang, F.Z.; Huang, L.; Xia, F.N.; Zhu, Y.R.; Wu, J.X.; Yin, J.; Yao, N.; et al. Arabidopsis acyl-CoA-binding protein ACBP3 participates in plant response to hypoxia by modulating very-long-chain fatty acid metabolism. Plant J. 2015, 81, 53-67. [CrossRef]

38. Hsiao, A.S.; Yeung, E.C.; Ye, Z.W.; Chye, M.L. The Arabidopsis cytosolic acyl-CoA-binding proteins play combinatory roles in pollen development. Plant Cell Physiol. 2015, 56, 322-333. [CrossRef]

39. Cregeen, S.; Radisek, S.; Mandelc, S.; Turk, B.; Stajner, N.; Jakse, J.; Javornik, B. Different Gene Expressions of Resistant and Susceptible Hop Cultivars in Response to Infection with a Highly Aggressive Strain of Verticillium albo-atrum. Plant Mol. Biol. Report. 2015, 33, 689-704. [CrossRef] 
40. Grieß, K.; Polanski, C.; Markgraf, D.; Lammert, E.; Roden, M.; Stark, H.; Brüning, J.; Belgardt, B. The role of ceramide synthases in pancreatic beta cell demise. Diabetol. Stoffwechs. 2018, 13, 18.

41. Tidhar, R.; Futerman, A.H. The complexity of sphingolipid biosynthesis in the endoplasmic reticulum. Biochimi. Biophys. Acta 2013, 1833, 2511-2518. [CrossRef] [PubMed]

42. Senkal, C.E.; Salama, M.F.; Snider, A.J.; Allopenna, J.J.; Rana, N.A.; Koller, A.; Hannun, Y.A.; Obeid, L.M. Ceramide Is Metabolized to Acylceramide and Stored in Lipid Droplets. Cell Metab. 2017, 25, 686-697. [CrossRef] [PubMed]

43. Grevengoed, T.J.; Klett, E.L.; Coleman, R.A. Acyl-CoA metabolism and partitioning. Annu. Rev. Nutr. 2014, 34, 1-30. [CrossRef] [PubMed]

44. Bravo-San Pedro, J.M.; Sica, V.; Martins, I.; Pol, J.; Loos, F.; Maiuri, M.C.; Niso-Santano, M.; Aprahamian, F.; Denom, J.; Kroemer, G.; et al. Acyl-CoA-Binding Protein Is a Lipogenic Factor that Triggers Food Intake and Obesity. Cell Metab. 2019, 30, 754-767. [CrossRef] [PubMed]

45. Manuel, B.; Valentina, S.; Frank, M.; Guido, K. Acyl-CoA-binding protein (ACBP): The elusive 'hunger factor' linking autophagy to food intake. Cell Stress 2019, 3, 312-318.

46. Manuel, B.; Valentina, S.; Isabelle, M.; Gerasimos, A.; Chiara, M.; Guido, K. Cell-autonomous, paracrine and neuroendocrine feedback regulation of autophagy by DBI/ACBP (diazepam binding inhibitor, acyl-CoA binding protein): The obesity factor. Autophagy 2019, 15, 2036-2038.

47. Patakova, P. Monascus secondary metabolites: Production and biological activity. J. Ind. Microbiol. Biotechnol. 2013, 40, 169-181. [CrossRef]

48. Chen, W.P.; He, Y.; Zhou, Y.X.; Shao, Y.C.; Feng, Y.L.; Li, M.; Chen, F.S. Edible flamentous fungi from the species Monascus: Early traditional fermentations, modern molecular biology, and future genomics. Compr. Rev. Food Sci. Food Saf. 2015, 14, 555-567. [CrossRef]

49. Feng, Y.; Shao, Y.; Chen, F. Monascus pigments. Appl. Microbiol. Biotechnol. 2012, 96, 1421-1440. [CrossRef]

50. Hajjaj, H.; Klaébé, A.; Goma, G.; Blanc, P.J.; Barbier, E.; François, J. Medium-chain fatty acids afect citrinin production in the flamentous fungus Monascus ruber. Appl. Environ. Microbiol. 2000, 66, 1120-1125. [CrossRef]

51. Bechman, A.; Phillips, R.D.; Chen, J. Changes in selected physical property and enzyme activity of rice and barley koji during fermentation and storage. J. Food Sci. 2012, 77, M318-M322. [CrossRef] [PubMed]

52. Sugiyama, S.I. Selection of micro-organisms for use in the fermentation of soy sauce. Food Microbiol. 1984, 1, 339-347. [CrossRef]

53. Hao, Q.; Liu, X.; Zhao, G.; Jiang, L.; Zeng, B. Recombinant expression, purification, and characterization of an acyl-CoA binding protein from Aspergillus oryzae. Biotechnol. Lett. 2015, 38, 519-525. [CrossRef] [PubMed]

54. Kwon, H.S.; Kawaguchi, K.; Kikuma, T.; Takegawa, K.; Higuchi, Y. Analysis of an acyl-CoA binding protein in Aspergillus oryzae that undergoes unconventional secretion. Biochem. Biophys. Res. Commun. 2017, 493, 481-486. [CrossRef] [PubMed]

55. Yao, G.; Yue, Y.; Fu, Y.; Fang, Z.; Xu, Z.; Ma, G.; Wang, S. Exploration of the regulatory mechanism of secondary metabolism by comparative transcriptomics in Aspergillus flavus. Front. Microbiol. 2018, 9, 1568. [CrossRef] [PubMed]

56. Mousavi, B.; Hedayati, M.T.; Hedayati, N.; Ilkit, M.; Syedmousavi, S. Aspergillus species in indoor environments and their possible occupational and public health hazards. Curr. Med. Mycol. 2016, 2, 36-42. [CrossRef] [PubMed]

57. Wang, P.; Chang, P.K.; Kong, Q.; Shan, S.H.; Wei, Q.J. Comparison of aflatoxin production of Aspergillus flavus at different temperatures and media: Proteome analysis based on TMT. Int. J. Food Microbiol. 2019, 310, 108-313. [CrossRef]

58. Chang, P.K.; Sui, H.; Siov, S.; Robert, L. Suppression of Aflatoxin Biosynthesis in Aspergillus flavus by 2-Phenylethanol Is Associated with Stimulated Growth and Decreased Degradation of Branched-Chain Amino Acids. Toxins 2015, 7, 3887-3902. [CrossRef]

59. Chen, X.P.; Li, H.F.; Liu, H.Y.; Hong, Y.B.; Yang, Q.L.; Chi, X.Y.; Yang, Z.; Yu, S.L.; Li, L.; Liang, X.Q. Transcriptome identification of the resistance-associated genes (rags) to aspergillus flavus infection in pre-harvested peanut (arachis hypogaea). Funct. Plant Biol. 2013, 40, 292-303.

60. Ratledge, $\mathrm{C}$. The role of malic enzyme as the provider of NADPH in oleaginous microorganisms: A reappraisal and unsolved problems. Biotechnol. Lett. 2014, 36, 1557-1568. [CrossRef] 
61. Yuzbasheva, E.Y.; Mostova, E.B.; Andreeva, N.I.; Yuzbashev, T.V.; Laptev, I.A.; Sobolevskaya, T.I.; Sineoky, S.P. Co-expression of glucose-6-phosphate dehydrogenase and acyl-CoA binding protein enhances lipid accumulation in the yeast Yarrowia lipolytica. New Biotechnol. 2017, 39, 18-21. [CrossRef] [PubMed]

62. Kwon-Chung, K.J. Morphogenesis of Filobasidiella neoformans, the sexual state of Cryptococcus neoformans. Mycologia 1976, 68, 821-833. [CrossRef] [PubMed]

63. Lin, X.; Hull, C.M.; Heitman, J. Sexual reproduction between partners of the same mating type in Cryptococcus neoformans. Nature 2005, 434, 1017-1021. [CrossRef] [PubMed]

64. Xu, X.; Zhao, Y.; Kirkman, E.; Lin, X. Secreted acb1 contributes to the yeast-to-hypha transition in cryptococcus neoformans. Appl. Environ. Microbiol. 2015, 82, 1069-1079. [CrossRef]

65. Micheletto, M.C.; Mendes Luís, F.S.; Basso, L.G.M.; Fonseca-Maldonado, R.G.; Costa-Filho, A.J. Lipid membranes and acyl-CoA esters promote opposing effects on acyl-CoA binding protein structure and stability. Int. J. Biol. Macromol. 2017, 102, 284-296. [CrossRef]

66. Mandrup, S.; Jepsen, R.; Skøtt, H.; Rosendal, J.; Højrup, P.; Kristiansen, K.; Knudsen, J. Effect of heterologous expression of acyl-CoA-binding protein on acyl-CoA level and composition in yeast. Biochem. J. 1993, 290, 369-374. [CrossRef]

67. Chao, H.; Martin, G.G.; Russell, W.K.; Waghela, S.D.; Russell, D.H.; Schroeder, F.; Kier, A.B. Membrane Charge and Curvature Determine Interaction with Acyl-CoA Binding Protein (ACBP) and Fatty Acyl-CoA Targeting. Biochemistry 2002, 41, 10540-10553. [CrossRef]

68. Han, J.Z.; Sun, Y.L.; Chen, Y.; Li, H.R.; Liu, M.M.; Zeng, B. Influence of Tags on the Binding Affinity of Acyl-CoA Binding Protein. Am. J. Biochem. Biotechnol. 2019, 15, 13-22. [CrossRef]

69. Kinseth, M.A.; Anjard, C.; Fuller, D.; Guizzunti, G.; Loomis, W.F.; Malhotra, V. The Golgi-associated protein GRASP is required for unconventional protein secretion during development. Cell 2007, 130, 524-534. [CrossRef]

(C) 2020 by the authors. Licensee MDPI, Basel, Switzerland. This article is an open access article distributed under the terms and conditions of the Creative Commons Attribution (CC BY) license (http://creativecommons.org/licenses/by/4.0/). 